\title{
Reverse Innovation Strategy: Local Technology Production Management Performance Booster Demand Trend Analysis
}

\author{
Prof. Dr. Ahmet Incekara (Istanbul University, Turkey) \\ Assoc. Prof. Dr. Elif Haykır Hobikoğlu (Istanbul University, Turkey)
}

\begin{abstract}
It was the most important condition of the competition in the information society to create high added value products. Additionally, the products with high added value are composed of the differentiated products that find the living area through the innovation leaded by the creativity. The innovation concept has been mostly perceived as developed country qualification. On the other hand, the reverse innovation provides opportunity for marketing the innovations belonged to the developing markets to entire world. The reverse innovation provides the extension of the market by reaching to the large population composed of people who cannot benefit from high developing countries. While the reverse innovation has been conveying the less qualified product and services that accomplish the same activity and provide cost advantage to the markets that have been developing but could not reach the product and services, it does not decrease the high quality product sales. It has reviewed the trend factors that define the telephone preferences providing local price advantage towards establishing the reverse innovation strategy by reviewing the demand structure of the mobile phone in the working telecommunication market.
\end{abstract}

\section{Introduction}

For Rastogi, the innovation appears by the implementation of new information for the production of goods and services. It should be targeted by the innovation to provide benefit for the economy towards increasing the difference between the values of goods and services and their costs. Innovation is to use the new technologic information and to provide development by using such resources as an additional vale to increase the difference between the cost values (Parag N. Rastogi, 1988).

According to Drucker, the innovation is based on the organized abandonment fact. Great changes occurred once in several centuries in the history affect the economic system. The most important miles stones are composed of finding printing houses, reform and renaissance period, invention of steam machine and current innovation age (Durucker, 1994).

It is the indicator of the success for the innovation to discover something that has not previously considered, to make something that has not been previously made and thanks to the innovations, by providing the profit increase to accelerate the development based on the competition power. By means of globalization, the pitch/demand for good has increased and homogenized accordingly. Under these circumstances, the price advantage is more than important for consumer. When the product and services are similar, the price pressure is increased, the prices are decreased and the profits are decreased. The unique solution is to present the innovations to the market by achieving profit increase through the innovations against the competition pressure. Innovation is established by a creativeness culture instead of research and development laboratory and advanced technology, the products including the low technology but active creativity could be a reason for the number of highest demands. The product should be designed in accordance with the requirements of the target mass as well as should be at the level where the price could be afforded by the target mass and the distribution channels should be selected to support the price structure (Kırıml1, 2006).

Overall innovations are available in the rich countries and flow into the developing countries however, in the reverse innovation, there was an innovation that goes opposite to the flow. We could say that the reverse innovation is each kind of innovation firstly applied in the developing countries.

The reverse innovation presents the product that provides price advantage by making concession from its performance and quality to the consumer group that does not buy the irrelevant product and services and it helps the low income group to come into market as a player.

In the study, the demand trend analysis was carried out under the direction of reverse innovation local telephone production. The road map in accordance with this strategy was established.

\section{Reverse Innovation Strategy}

Nowadays, approximately 7 billion people are living in the word. Only 1 billion is the consumer and the rest 6 billion could not consume anything. Most of 6 billion people have been living in the developing countries such as India, China and Turkey. It is a first number opportunity for the development to solve the problem for nonconsumers. When you solve the problem of people in need, it means that you have a product with reasonable price. For example; if you produce a product for a rich man, everyone could not purchase this product. However, 
if you produce a product for a poor man, at that time, everybody could purchase this product. Because, if a poor man can purchase this, the rich man could purchase as well. Hence, the product could be achieved by everyone. You could change entire world in this regard. According to the research, 85\% of people are living in the poor countries. In this sense, the companies that will make investment to the developing countries could not apply the methods in the rich countries. For example, if a person has 10 dollars in the rich countries, there are ten people who have 1 Dollars in the poor country. In a nutshell, it is not the reality to wait for the same condition between the rich and poor countries in terms of consumption behavior. For this reason, it could not be considered that the products and services of the rich countries will have a great effect on the poor countries (Govindaranjan, Chris, 2012). One of the most important reasons for decreasing the sales activities of the rich countries in the poor country markets is the income level of the societies and different requirements. There is no doubt that the parameters are not the same between the markets where a person could spend 100 Dollars but 100 people could spend 1 Dollar. For this reason, it is not right approach to wait for the product sustainability of rich countries in the poor country markets (Trimble \& Govindarajan, 2012).

Reverse innovation is every kind innovation applied in the developing countries. It could not be accepted in the developing markets so that product requirements of the rich countries are completely different. At this point, the reverse innovation gains acceleration. The reverse innovation presents a value that has been ignored for long years. It is more than important to realize the requirements and opportunities of the developing countries. Two third of the development around the world will come from the poor countries in ten and twenty years. There are many people who spend little money in the developing countries. At this point, the total expenditure is larger. The reverse innovation begins with forget but not innovation. It is really important to focus on the needs that have not been met in the developing country and to solve them accordingly. The developing countries do not request for the high performances that have been demanded in the developed countries. The developing countries are very keen on the technologies that provide sufficient performance with low costs. The developed countries have large infrastructural possibilities. The lack of infrastructure in the developing countries could be an opportunity for the reverse innovation developments. The developing countries could achieve environmental safe technologies for providing sustainable development. Due to the fact that the legal arrangements in the developing countries are less developed, the innovative solutions could be applied simply. By considering the interests and preferences of the countries, it will help to benefit from the advantages of new innovations for the reverse innovation. The developed countries provide important opportunities. The reverse innovation provides global effect. The reverse innovation provides a trend towards closing the differences among the regions. In order to cover the market needs, the reverse innovation that provides low cost and ease of use having similar performance with the expensive product and it provides a trend towards covering the requirement needs. The reverse innovation dynamics will be successful if it becomes a part of the strategy dialogue in the multinational companies. The reverse innovation is the best solution for the market customer under the development. It establishes new basic abilities, new consumers and it provides low price and high volume, it develops product for the solution of the consumers 'problems as well as it established new basic qualifications and it provides development processes for the developing markets .(Govindarajan and Trimble, 2012)

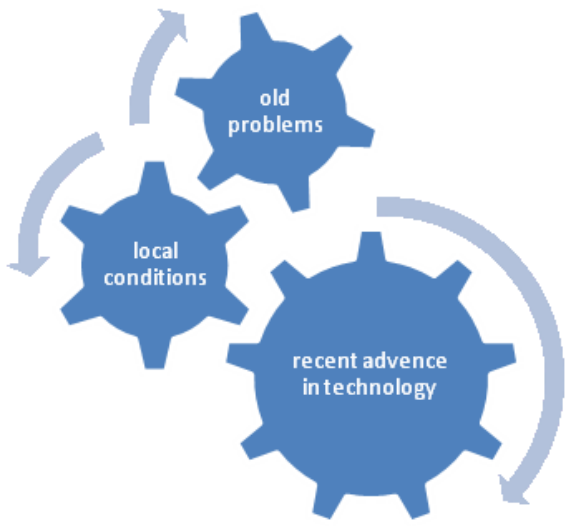

Figure 1. Creative Solution Gear

Reverse innovation is a market focused approach. It attempts to produce relevant solutions for the consumer needs of the countries respectively. Most of the reverse innovation is the business model innovation. New processes, partnership and re-created value chain are required. The strongest reverse innovation is the platform innovations that could decrease and increase the scales as if meeting the various price points. The reverse innovation requires the redesign the innovation and product accordingly.

In order to establish reverse innovation mind, the businesses should focus on the developing markets in the first step and they should develop their information and expertise about the developing markets and they should emphasize the changes that could be easily recognized by the symbolic personal movements. 
The reverse innovation is based on the weight shifting strategy. The most important decision makers are settled in low income countries. By establishing new senior management offices that will observe the developing markets, the performances as well as profit and losses should be assessed. In the developing markets, the research and development expenditures focused on the local needs should be increased. The information and expertise about the developing markets should be increased. It helps to understand the consumer problems in the countries with the low income level and it transfers information and skills to those countries. It increases the social ties between the developed countries and developing countries and it strengthens the strategy of the reverse innovation.

On the ground of the reverse innovation, it is focused on that the consumers will be more than happy by a product with the low cost without considering the quality.

Establishment of the local development teams is very important for reverse innovation: The persons and factors that will provide solution for the developing markets should be convened. The sales and marketing should be integrated with the research and development. It is also important to reach the relevant new abilities and skills about the issue.

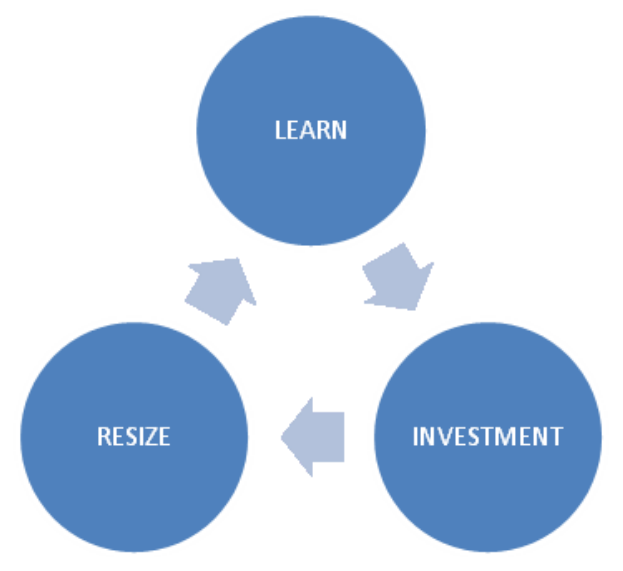

Figure 2. Local improvement team fast and low cost circle

Low priced products will provide the demand between the people who will never buy high priced costs. The reverse innovations provide the demand between the people who have never been served by the services. By emphasizing the reasons of the consumer dissatisfaction, the solution must be achieved in this regard.

On the other hand, it is important to have the information in the local level and to transfer them to the global level. The price, size, frequency of occurrence and consumer income combination should be well analyzed.

\section{Research Goal, Analyses and Results}

In our study where the telecommunication market has been reviewed, 820 surveys have been applied to people selected by unconfined sample. Our target is everybody who wants to have mobile phone and the survey was made in accordance with the random selection method. The research was made in the Anatolian side of Istanbul. The purpose of this research is to define the attitudes towards reverse innovation strategy about the preferences of the local mobile phones in accordance with their mobile phone requirements of people living in Anatolian Site of Istanbul. 1000 survey forms were distributed and 820 of them were approved by the analysis.

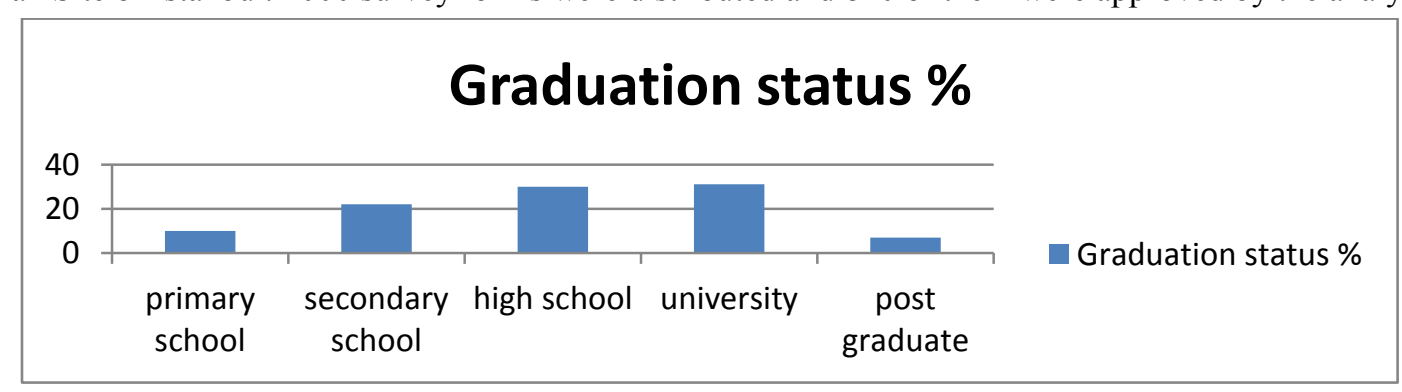

Figure 3. Educational Level

While $38 \%$ of people who participated in the study were graduated from the university and post graduate, $52 \%$ was graduated from high school and intermediary school, \%10 was graduated from primary school. The rate of non-university and master graduation is about $62 \%$. 


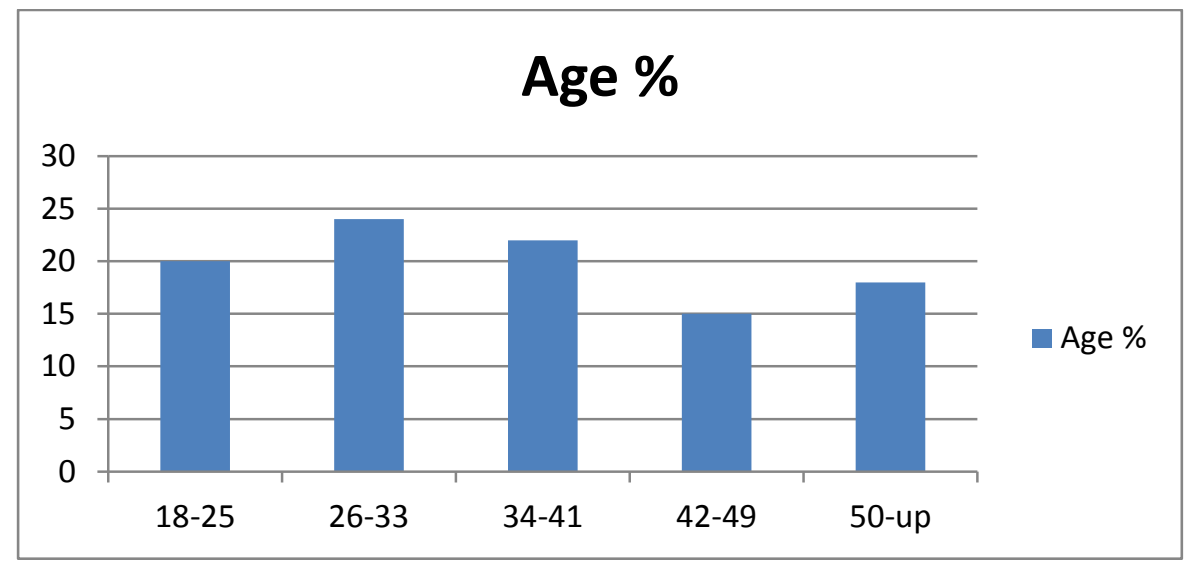

Figure 4. Age

$20 \%$ of people who participated in the study are between $18-25,24 \%$ is between $26-33,22 \%$ is between $34-41$, $15 \%$ is between $42-49,18 \%$ is more than 50 . The participation rate is about $61 \%$ between $26-49$.

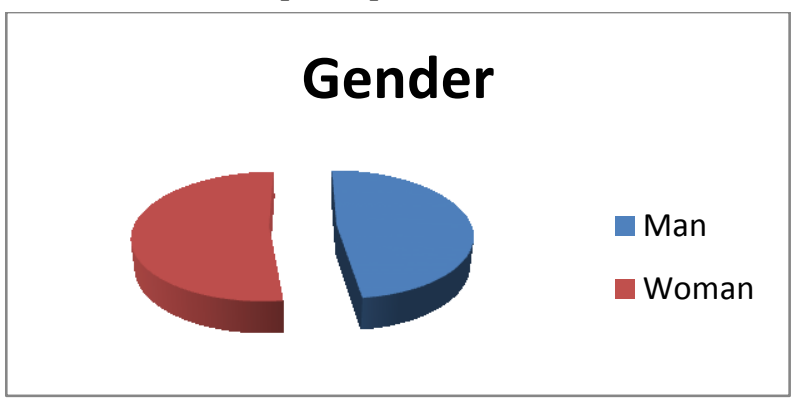

Figure 5. Gender

$48 \%$ of people who participated in the study is composed of men, $52 \%$ is composed of women population.

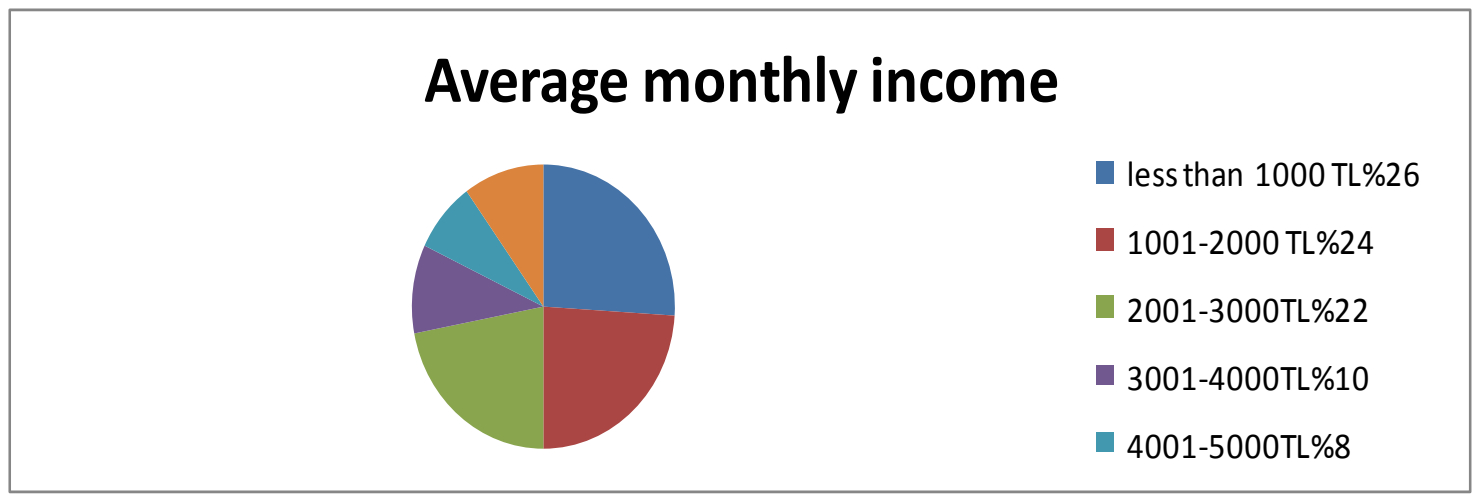

Figure 6. Monthly average income

While only $10 \%$ of people who participated in the study have been earning monthly average income more than 5000TL, per capita income in Turkey in 2014 is about 10.000 US Dollars. 50\% of people who participated in the study in Turkey where the per capita monthly income is $2.250 \mathrm{TL}, 50 \%$ of people participated in the study in Turkey has income lover than this income, $28 \%$ of people has $3.000 \mathrm{TL}$ and more accordingly. 


\begin{tabular}{|l|c|}
\hline \multicolumn{1}{|c|}{ Specification } & Importance rate \\
\hline Price advantage & $83 \%$ \\
\hline Charge time & $82 \%$ \\
\hline Ease of using & $81 \%$ \\
\hline Internet speed and ease of internet using & $76 \%$ \\
\hline Touchscreen & $74 \%$ \\
\hline Battery life & $71 \%$ \\
\hline Screen size (inch) & $52 \%$ \\
\hline Talking time (hour) & $48 \%$ \\
\hline Weight & $38 \%$ \\
\hline Trademark & $33 \%$ \\
\hline Camera specifications & $29 \%$ \\
\hline Image resolution & $28 \%$ \\
\hline Resolution & $\% 27$ \\
\hline Process rate & $\% 26$ \\
\hline Operating system & $\% 20$ \\
\hline Ram & $\% 12$ \\
\hline Core & $\% 10$ \\
\hline
\end{tabular}

Table 1. The most important specification orders that directs the preferences for buying mobile phone

The participants could mark more than one option. The most important specification in the smart phones is the price advantage by $82 \%$ and the charge time is in the second rank as well as the ease of using is in the third rank and internet speed and internet using on the phone is in the fourth rank accordingly. Comparing the smart phone imports with the local phones in terms of technology will develop the local production and exporting activities and it helps to produce local smart phones that cover the phone requirements in the developing countries and exporting activities as well in term of saving. In order to apply a reverse innovation in the smart telephone sector, the demand requirement should be effectively directed and should be researched.

The applications percent that has been mostly used in the smart mobile phones

\section{Demand side order of preference}

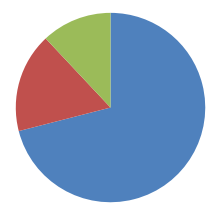

- Price advantage

Brand

Material quality

Figure 7. Preference order of Demanded Mobile Phone

$71 \%$ of the target mass that is adapted with the reverse innovation that participated in the study emphasizes the price importance. While $17 \%$ considers that the trademark of the mobile phone is important, only $12 \%$ is focused on the material quality of the mobile phone.

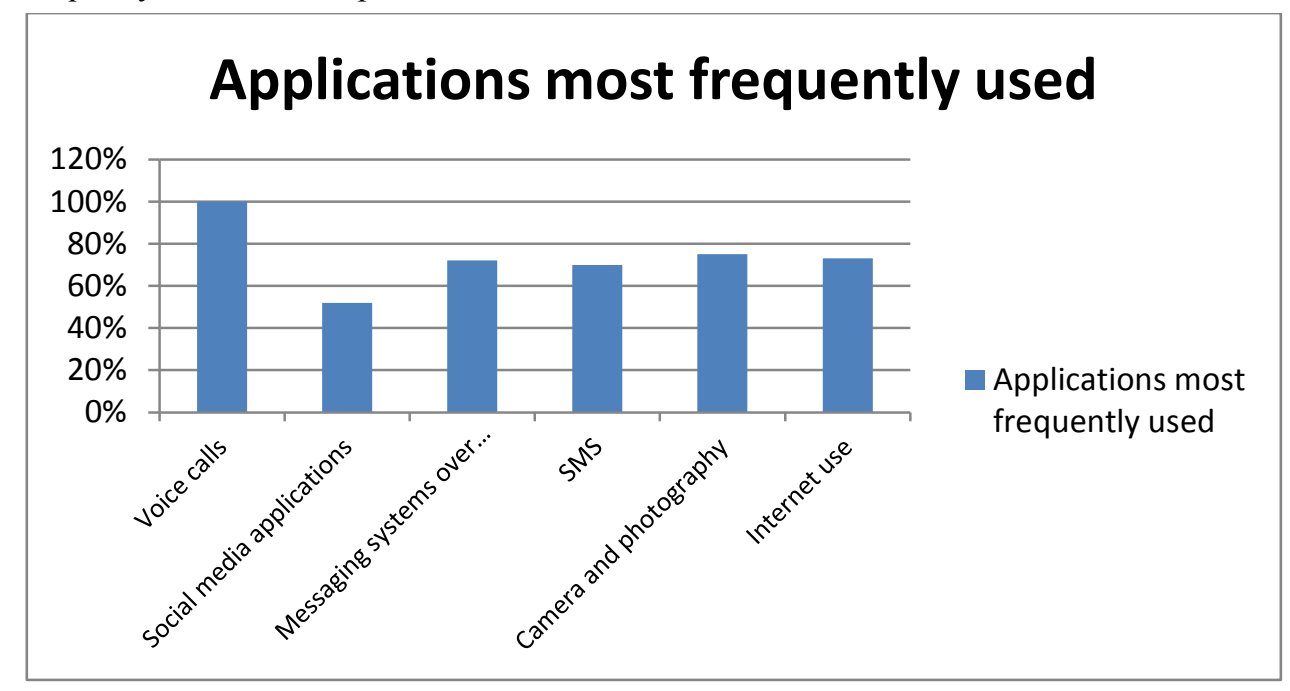

Figure 8. The most preferred mobile phone functions 
When considering the most preferred mobile phone function, $100 \%$ of people who participated in the study have been using the mobile phone as the voice communication tool and $75 \%$ is focused on the messaging systems and image applications on the internet. 52 percent of people who participated in the study consider that mobile phone is a social media tool. The most important specifications for the mobile phones are respectively voice talking, camera, taking photo, internet using, messaging system on the internet, SMS and social media.

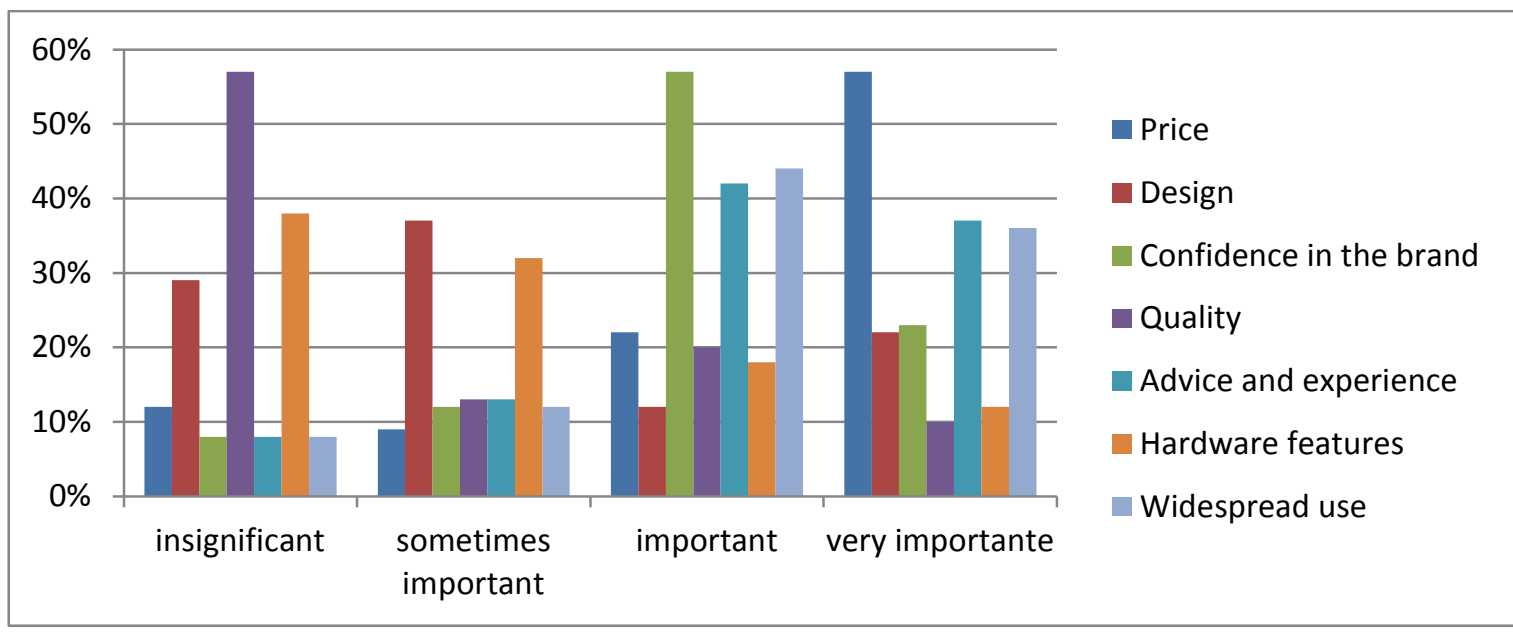

Figure 9. The factors that provide smart phone demand trends

While purchasing the mobile phone, the factors that have been considered effective on people are respectively sorted. The price having $57 \%$ rate is in the first and important rank, the quality is the least significant factor. Due to the fact that the mobile phone change rate is high and material quality is high and the number of mobile phone that is still active have not been used, the quality factor is seen as the least significant in the demand structure.

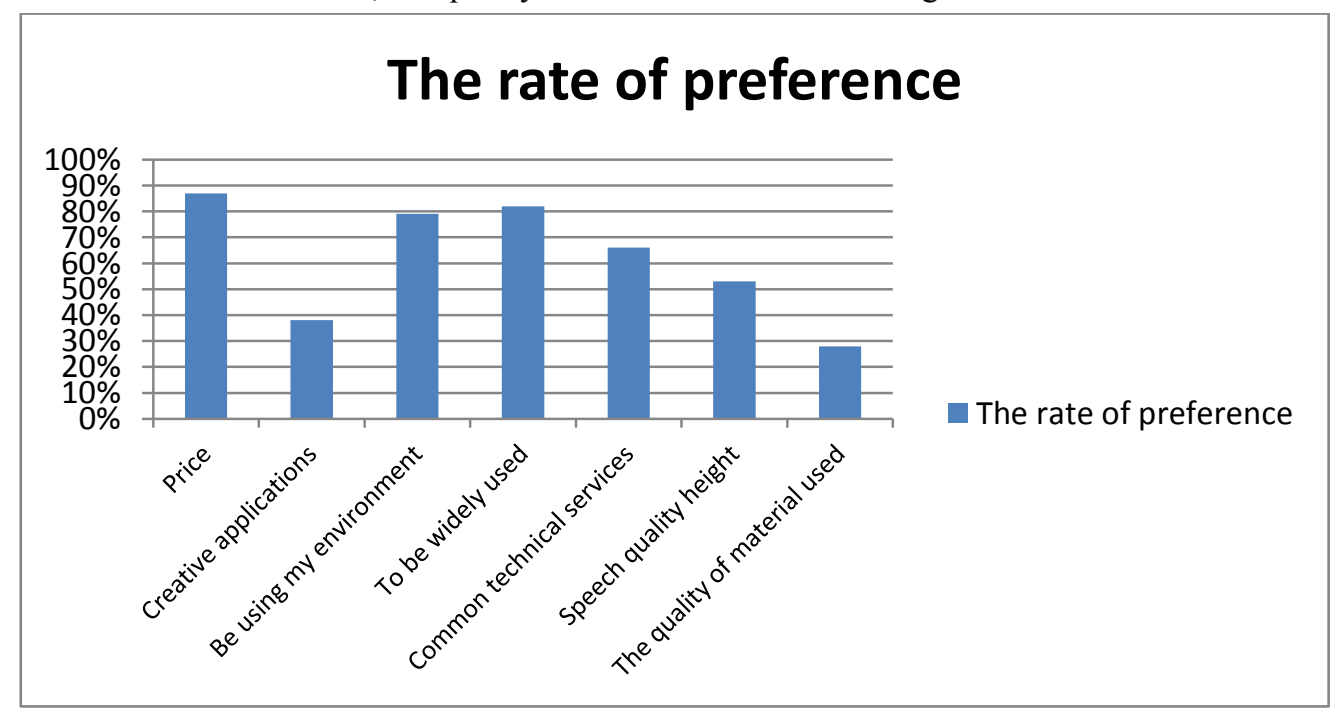

Figure 10. The elements that tiger the purchasing trend for local produced mobile phone

In the study where the limited function of the mobile phones are used and where consumer attended whose monthly income is under $5000 \mathrm{TL}$, there are three basic preference points that will affect positively the trend of local mobile phone procurement. $87 \%$ of people who participated in the study emphasized that they could prefer local production if there is any price opportunity, $82 \%$ said that they could buy local production if the local mobile phone has larger using area and $79 \%$ of people defined that they could prefer this production if people around they prefer such phones. While producing mobile phone, we could face with a factor that is ignored about the quality at the rate of $28 \%$.

\section{Conclusion}

We can define the reverse innovation as to make innovation for the consumers with low income in the developing countries then to market these products that could be purchased by everyone all around the world. The production of the goods and services that could cover the consumer requirements and that has best analyzed and that provides price advantage to be designed for the consumers with the low income have replaced with the unsalable products if the high price and utilization could not be paired. The innovation capacity for the 
developing capacity by means of the reverse innovation strategy has not affected the product sales in the high quality and high price and it opens a new market for itself.

$62 \%$ of people who participated in the study were not graduated from university, $72 \%$ has monthly income under 3000 TL. For approximately 80 percent of people who have above mentioned demographic specifications, the price advantage, charge time and ease of using are more than important for the preference of the mobile phone. $82 \%$ indicated that it is also important if the local produced mobile phone has common usage network. For people who have low income, the mobile phones that have been produced by the local resources could achieve to the global market.

Consequently, it was analyzed that in comparison with the high technologic mobile phones, the local production mobile phones that provide high rated price advantage, long battery life, ease of using, voice communication, messaging service on the internet such as whatsup etc. and that have camera specifications without taking into the consideration of resolution could be preferred by the consumers whose monthly incomes are under 3000TL. In the second step, when disseminating the above mentioned functions and the production that provide large area of use by means of advertisement and public relations, positive suggestions and sharing the experiences about the product, the promotional activities about the area of use, these will increase the preference rate of the local mobile phones. Due to the fact that people tend to use the popular telephone trademarks that have been used by their relatives and friends, the success could be achieved by means of the reverse innovation strategy by supporting the mobile phone procurements together with the social environment and by providing moral and material support. The reverse innovation strategy starting from the local could begin a global current towards the developing countries.

\section{References}

- Arman Kırımlı, 2006. Karlı Büyümenin Reçetesi İnnovasyon, Sistem Yayıncılık, İstanbul.

- Carlson C, Wilmont W, 2006. Innovation The Five Disciplines for Creating What Customers Want, Raymond, New York.

- Govindarajan V, Trimmple C. 2012. Reverse Innovation, Harward Business Review Press, Boston, Massachusetts

- Parag N. Rastogi, 1988. Productivity, Innovation, Management and Development, Sage Publication, California.

- Peter Durucker, 1994. Kapitalist Ötesi Toplum, Inkılap Kitapevi, İstanbul.

- Trimble C, Govindarajan V. 2012. Reverse Innovation: Create Far From Home, Win Everywhere. Harvard Business School Press Books, Boston, Massachusetts

- $\quad$ http://stratejikplanlama.net/gelir-ucurumunu-ters-inovasyon- (12.3.2015) 